\title{
Relações de gênero no ensino de sociologia do IFSul ${ }^{1}$
}

\author{
Gender relations in sociology teaching \\ at IFSul
}
Relaciones de género en la enseñanza de sociología del IFSul

\author{
ANDRÉIA ORSATO* \\ Instituto Federal Sul-Rio-Grandense, Pelotas, RS, Brasil. \\ MÁRCIA ONDINA VIEIRA FERREIRA** \\ Universidade Federal de Pelotas, Pelotas, RS, Brasil.
}

\begin{abstract}
RESUMO: O texto trata do debate acerca das relações sociais de gênero no ensino de sociologia no IFSul, destacando o espaço destinado ao tema nos currículos e as metodologias empregadas pelos docentes ao abordá-lo. A partir de análise documental (grades curriculares e programas da disciplina) e de respostas a questionários aplicados aos professores podemos afirmar que o debate se centra na questão da mulher e está presente de forma transversal ou com espaço específico em grande parte dos programas, além de que diversas estratégias de ensino são utilizadas em sua abordagem.

Palavras-chave: Relações sociais de gênero. Ensino de sociologia. Currículo. IFSul.
\end{abstract}

\begin{abstract}
The text addresses the debate about gender social relations in sociology teaching at IFSul, highlighting the designated space to the theme in curricula and the methodology employed by
\end{abstract}

* Doutora em Ciência Política pela Universidade Federal do Rio Grande do Sul. Atua como docente no ensino médio e superior no Instituto Federal Sul-Rio-Grandense. Realizou estágio pós-doutoral no PPGE-FaE da Universidade Federal de Pelotas. E-mail: andreiaorsato@gmail.com.

* Doutora em Sociologia pela Universidade de Salamanca, Espanha, e pós-doutora pela Faculdad Latinoamericana de Ciencias Sociales, Argentina. É professora do corpo permanente do Programa de PósGraduação em Educação da Universidade Federal de Pelotas. E-mail: marciaondina@uol.com.br. 
faculty to approach it. Through documental analysis (curricular programme and syllabus) and answers to questionnaires applied by teachers, we can affirm that the debate is focused on woman's issues and is present in a transversal way, or with specific space in the majority of the programs. Moreover, various teaching strategies are used in its approach.

Keywords: Social gender relations. Sociology teaching. Curriculum. IFSul.

RESUMEN: El texto trata del debate respecto de las relaciones sociales de género en la enseñanza de sociología en el IFSul, destacando el espacio destinado al tema en los currículos y las metodologías empleadas por los docentes al plantearlo. A partir de análisis documental (planes curriculares y programas de la asignatura) y de respuestas a cuestionarios aplicados a los profesores, podemos afirmar que el debate se centra en la cuestión de la mujer y está presente de forma transversal o con espacio específico en gran parte de los programas, además de que se utilizan diversas estrategias de enseñanza en su enfoque.

Palabras clave: Relaciones sociales de género. Enseñanza de sociología. Currículo. IFSul.

\section{Introdução}

E ste trabalho reflete sobre o ensino de sociologia e o debate em torno das relações sociais de gênero a partir das experiências educacionais desenvolvidas nos onze campi do Instituto Federal Sul-rio-grandense (IFSul) que oferecem ensino técnico integrado.

Para compreender o contexto do qual se fala, é preciso primeiramente dizer que há uma produção consistente a respeito das disputas sobre a inclusão da disciplina de sociologia nos currículos do ensino médio brasileiro. A querela inicia em finais do século XIX e segue até os dias de hoje, demonstrando as descontinuidades na obrigatoriedade desse componente curricular a partir das reformas educacionais levadas a termo pelos diferentes governos (CARVALHO, 2004; OLIVEIRA, 2014; SILVA, 2010; entre outros).

Atualmente observa-se novo revés, considerando a aprovação da Lei nº 13.415/2017, que altera a Lei de Diretrizes e Bases da Educação Nacional (LDB) e sugere uma distinta organização para o ensino médio dividida em duas etapas: na primeira seriam ofertadas 
as disciplinas obrigatórias constantes na Base Nacional Comum Curricular (BNCC); na segunda o aluno poderá escolher seu itinerário formativo a partir de cinco eixos, mantendo como obrigatórias em todos os anos as disciplinas de arte, língua inglesa (incluída), língua portuguesa e matemática. A sociologia aparece no Artigo 35-A, acrescido à LDB, onde se lê que a BNCC referente ao ensino médio incluirá obrigatoriamente estudos e práticas, entre outros, de sociologia e filosofia. A disciplina deixa de ser obrigatória nos três anos do ensino médio e, mesmo que a BNCC a apresente como obrigatória, mudanças nessa legislação poderiam causar insegurança, haja vista que a nova LDB alude apenas à obrigatoriedade de "estudos e práticas" dos conhecimentos sociológicos.

À história da sociologia e à atual incerteza quanto ao seu futuro nas escolas brasileiras somam-se outras problemáticas de estudo em torno da disciplina. Os esforços têm se concentrado nas formas como vem sendo ministrada em termos de carga horária, metodologias de ensino-aprendizagem, materiais didáticos, profissionais que atuam no ensino, formação de professores e conteúdos curriculares.

Considerando que não existe um programa nacional comum para o ensino de sociologia, este trabalho pretende contribuir para os estudos da área, analisando como o debate sobre gênero se faz presente na disciplina desenvolvida nos diferentes cursos técnicos oferecidos pelo IFSul, priorizando a análise do espaço e das metodologias empregadas pelos docentes ao abordar o tema.

A fim de atingir esses objetivos, a metodologia aplicada na investigação foi o protocolo quali-quantitativo, utilizando-se a análise documental (de grades curriculares e programas da disciplina) e as respostas de questionários enviados por E-mail ou aplicados pessoalmente aos docentes da disciplina². Assim, neste texto apresentamos, em primeiro lugar, uma análise do sentido da presença da sociologia nos currículos de ensino médio e de como o gênero pode colaborar para as problematizações específicas da disciplina. Na sequência, discutimos o caso específico estudado na pesquisa que deu origem ao texto, voltando-nos aos resultados da presença do gênero no desenvolvimento da sociologia nos cursos técnicos do IFSul. À guisa de conclusão, destacamos que de forma explícita ou apenas transversalmente o gênero tem estado presente nos currículos analisados, mesmo quando restrito às problemáticas sociais das mulheres.

\section{A sociologia no ensino médio e o debate sobre gênero}

A inclusão da sociologia no ensino médio tem se justificado não apenas pela sua capacidade de instrumentalização para a formação cidadã, mas também e, sobretudo, por ser uma ciência cujo conhecimento específico tem por finalidade contribuir, através da consciência discursiva (OLIVEIRA, 2014), para o estranhamento e desnaturalização da realidade social, problematizando aspectos da vida social internalizados "pela 
ciência, pelos costumes, pela tradição, pelas religiões, pela política etc" (PASSAMANI 2016, p.214).

Ou, ainda, nas palavras de Osório e Sarandy (2016, p.71), segundo os quais, a finalidade da sociologia seria

[...] desenvolver uma nova atitude cognitiva, um modo específico de olhar e compreender a realidade social e humana, a apropriação de uma abordagem da experiência humana. Essa atitude cognitiva é definida pelos modos de raciocínio desenvolvidos no campo científico das Ciências Sociais: um olhar que estranha o real, pois compreende que ele não é um dado; que desnaturaliza os fenômenos humanos e sociais e recusa explicações essencialistas e naturalizantes.

Uma forma de compreender a sociedade e suas representações, para além do senso comum, pode ser realizada através de debates sobre gênero, sexualidade e diversidade sexual, pois tais temáticas "dizem muito a respeito das relações sociais e da organização da vida social como um todo" (MATOS; SCHMIDT; ARANTES, 2013, p.212). Mesmo fazendo parte do cotidiano, inclusive escolar, o debate sobre gênero, de maneira geral, é pouco abordado pelas instituições de ensino (FERREIRA, 2016). Contudo, sua inserção vem sendo ampliada nos últimos anos no campo educacional por conta das intervenções de movimentos sociais, como o feminista e o LGBT, que, junto ao Estado, buscaram garantir seus interesses e, em especial, construir espaços para que esse debate pudesse ter lugar nos currículos escolares (ARAUJO, 2016, p.5).

A despeito disso, alguns estudos têm demonstrado que o debate sobre gênero não tem surtido efeito nos documentos nacionais que norteiam a educação básica no País, em particular no que se refere ao ensino de sociologia. Um exemplo pode ser encontrado em Vianna e Unbehaum (2004), as quais, ao analisarem a Constituição Federal (1988), a LDB, o PNE (Plano Nacional de Educação - 2001) e os PCN (Parâmetros Curriculares Nacionais - 1997), concluíram que tais documentos apresentam o debate sobre gênero de "modo velado, ambíguo e, às vezes, reducionista" (VIANNA; UNBEHAUM, 2004, p.101), ficando restrito às questões legais de direitos e valores.

Nos PCN a discussão sobre gênero está alocada nos "Temas Transversais" em uma sessão nomeada "Orientação Sexual". O fato de não haver menção detalhada e explícita do tema no documento e jogar o debate para o campo da transversalidade, segundo Araujo (2016), pode fazer com que gênero incida no esquecimento e que, juntamente com sexualidade, se restrinja à prevenção da gravidez e às doenças sexualmente transmissíveis, inviabilizando a discussão sobre assimetrias de gênero, sua construção histórica e da sexualidade nos corpos. Mesmo que presentes nas escolas, tais questões são aventadas como pertencentes à vida privada. Desse modo, "a negligência ao se tratar desses temas nas escolas denota um conjunto de práticas que oficializam a heterossexualidade e a classificação dos corpos como masculino e feminino, baseando-se no sexo biológico como prática normatizadora da conduta no interior da escola" (ARAUJO, 2016, p.6). 
Ao analisar documentos que orientam o ensino de sociologia: PCN, Organização Curricular Nacional (OCN) e a BNCC, Osório e Sarandy (2016), afirmam que mesmo que o debate sobre gênero seja um "[...] tema multidisciplinar, é uma área consolidada de estudos nas Ciências Sociais e, desse ponto de vista, entende-se que tal debate deveria estar alocado (também e não tão somente) nos conteúdos sociológicos" (OSÓRIO; SARANDY, 2016, p.59).

A análise dos documentos citados reflete a ausência da questão de gênero, especialmente no âmbito dos temas a serem tratados pela sociologia. Segundo afirmam os autores (o que pode ser verificado), o PCN relativo aos conhecimentos de sociologia, antropologia e política em momento algum menciona a categoria gênero como instrumento para problematizar e pensar a sociedade e o mundo. Fato parecido ocorreu quando os autores verificaram a seção específica de sociologia da OCN, a qual apresenta a categoria gênero, juntamente com sexualidade, em um único momento, qual seja, entre os temas que podem ser incluídos nos programas da disciplina, quando trabalhada pelo viés temático. "Assim, gênero emerge como um tema possível de ser trabalhado em sala de aula, mas não como um tema necessário" (OSÓRIO; SARANDY, 2016, p. 66). O exame da BNCC não alterou muito o quadro. Ao definir os conceitos sociológicos básicos, gênero e relações sociais de gênero "não são considerados nem básicos nem importantes e presumimos que sejam componentes invisibilizados de "relações sociais", desigualdades e diversidade" (OSÓRIO; SARANDY, 2016, p.68). Assim, concluem, a BNCC é coerente com os PCN na medida em que reproduz a ideia de que gênero é uma categoria restrita à questão de tolerância à diversidade na sociedade.

Na análise das Diretrizes Curriculares Nacionais da Educação Básica (DCNEB) observamos que há inúmeras menções à necessidade do debate sobre questões de gênero nas escolas, por vezes associado à ideia de igualdade de oportunidades, de direitos, não discriminação, etc. O documento afirma a importância de "problematizar o desenho organizacional da instituição escolar, que não tem conseguido responder às singularidades dos sujeitos que a compõem" (BRASIL, 2013, p.16). Dessa forma, afirma ser impreterível a discussão de princípios e práticas que garantam acesso e considerem "a diversidade humana, social, cultural, econômica dos grupos historicamente excluídos. Trata-se das questões de classe, gênero, raça, etnia, geração, constituídas por categorias que se entrelaçam na vida social"' (BRASIL, 2013, p.16). Parece-nos importante verificar que gênero surge como uma categoria para a compreensão dos processos sociais, podendo ser vinculada a outras categorias analíticas.

Especialmente nas diretrizes nacionais para o ensino médio, o texto assegura o papel da educação como promotora, entre outros, " [...] do respeito à pluralidade e à diversidade de nacionalidade, etnia, gênero, classe social, cultura, crença religiosa, orientação sexual e opção política, ou qualquer outra diferença, combatendo e eliminando toda forma de discriminação" (BRASIL, 2013, p.165). Salienta ainda que o projeto político-pedagógico 
das escolas de ensino médio precisa ponderar a promoção dos direitos humanos a partir de alguns temas, entre os quais gênero, identidade de gênero e orientação sexual, "bem como práticas que contribuam para a igualdade e para o enfrentamento de todas as formas de preconceito, discriminação e violência sob todas as formas" (BRASIL, 2013, p.179).

Podemos compreender do exposto que, apesar dos entraves nas orientações das políticas nacionais para a educação, no debate sobre gênero, a disciplina de sociologia pode contribuir para a promoção da igualdade de gênero e construção de uma educação não sexista. Não obstante, como observou Burille (2015), os obstáculos nos processos de ressignificações das relações sociais por vezes dificultam "confrontar o preconceito de gênero e assim propor uma educação transformadora, à medida que a escola é espaço de reprodução das estruturas sociais atravessadas por um sistema de ensino tradicional e conservador" (BURILLE, 2015, p.221).

Tal perspectiva pode ser observada na nova BNCC para a educação básica no Brasil (excetuado o ensino médio, o qual não consta no documento), encaminhada no início de 2017 ao Conselho Nacional de Educação. O texto menciona em raras exceções o termo gênero, limitando-se a associá-lo à noção de respeito à diversidade. "[...] a diversidade - cultural, étnica, de gênero, entre tantas outras - deve ganhar especial destaque, com vistas ao acolhimento da diferença" (BRASIL, 2016, p.305). O texto, ao retirar termos como "identidade de gênero" e "orientação sexual", atendeu a uma demanda de determinados setores da sociedade, mas sofreu críticas por parte das organizações voltadas à educação no País, movimentos sociais e grupos ligados ao tema, denotando uma retração do debate e da importância dessa discussão em sala de aula.

Nesse sentido, verificamos iniciativas legislativas inspiradas no Projeto Escola Sem Partido, que visam interferir nos conteúdos trabalhados nas escolas, coibir e mesmo criminalizar docentes que trabalhem com questões relativas a gênero, a partir da visão de que esses executariam uma doutrinação ideológica e política, chamada, então, pelo fundamentalismo conservador, de "ideologia de gênero". Em 2015 havia pelo menos cinco projetos nesse sentido tramitando no Congresso Nacional (FERREIRA, 2016). Em 2016 ao menos 19 estados da federação apresentavam iniciativas legislativas com este conteúdo, em nível estadual ou municipal (MARINHO; IERVOLINO; NICOLAV, 2016), buscando, entre outros, retirar dos planos estaduais e/ou municipais de educação referências à identidade de gênero, diversidade e orientação sexual. Não obstante o Ministério Público Federal, a Advocacia-Geral da União e o Ministério da Educação tenham se pronunciado pela inconstitucionalidade de tal legislação, conforme Rosa (2017), é maior do que 70 o número atual de projetos de lei dessa natureza em análise nos diferentes âmbitos do Poder Legislativo brasileiro.

Para Ferreira (2016, p.7-8), o temor à "chamada "ideologia de gênero" inspira as bancadas religiosas a bloquear iniciativas de combate à discriminação racial, de orientação 
sexual ou à identidade de gênero no campo educacional, descortinando um cenário de retrocesso da sociedade".

Assim, compreendendo o currículo como um espaço de poder e construção sociocultural, podemos reafirmar que as controvérsias em torno da pertinência do debate sobre gênero no ambiente escolar são reflexo das disputas sociais, econômicas, políticas e ideológicas acerca dos temas que merecem ou não ser ministrados, que podem ou não ser debatidos, que devem ou não ser acessados pelos jovens em idade escolar. " $\mathrm{O}$ silêncio sobre determinados conteúdos - sua ausência - acaba por funcionar também como base de um currículo que sempre e necessariamente refletirá relações de dominação na sociedade" (OSÓRIO; SARANDY, 2016, p.69).

\section{O caso do IFSul}

Para pensar o desenvolvimento da sociologia desde o ponto de vista do currículo, verificamos o espaço destinado à disciplina nas grades curriculares dos cursos técnicos integrados de nível médio do IFSul e os conteúdos ministrados no âmbito da disciplina. O IFSul oferece 36 desses cursos em 11 de seus 14 campi, apresentando uma grande variedade em termos de área de atuação ${ }^{3}$.

Ao analisar as grades curriculares, identificamos que a carga horária destinada à sociologia é de 40 horas/aula em grande parte dos cursos, independentemente de a organização curricular ser anual (1hora/aula semanal) ou semestral (2horas/aulas em semestres intercalados) ${ }^{4}$. Tal situação é semelhante à adotada em outras escolas, onde via de regra a disciplina dispõe de apenas 1 hora/aula semanal (OLIVEIRA, 2014; SILVA, 2010), reflexo das disputas em torno do currículo que, em especial nas escolas técnicas, não levam em conta a importância do conhecimento sociológico para apreender a ação humana, a realidade do sujeito, comprometer-se e responsabilizar-se para com a sociedade, questões para além da formação técnica (COSTA, 1997).

Além da inserção da sociologia nos currículos escolares, outra questão pertinente é a composição programática da disciplina. Não havendo um currículo nacional comum, cada campi/professor tem autonomia para a elaboração dos conteúdos a serem ministrados; assim, a partir da análise dos programas, observamos um total de 26 assuntos/ temas trabalhados ao longo da formação discente no IFSul, quais sejam: "Cultura" (único constante nos programas de todos os campi); "Mundo do trabalho"; "Surgimento da sociologia"; "Poder e política"; "Desigualdades sociais"; "Gênero"; "Clássicos da sociologia"; "Movimentos sociais"; "Indivíduo e sociedade”; “Cidadania”; "Globalização"; "Pesquisa social"; "Relações sociais e raciais"; "Meios de comunicação de massa"; "Minorias sociais"; "Conceitos básicos"; "Meio ambiente"; "Cidades"; "Conhecimento"; "Religião"; "Sociologia e pós-modernidade"; "Mudança social”; "Questão geracional”; 
"Produção textual sociológica"; "Sociedade da informação" e "Interpretações do Brasil". Feito o mapeamento dos temas elencados, verificou-se que, além da variedade, os assuntos não são tratados da mesma forma em todos os campi, havendo uma subdivisão em cada item de acordo com a preferência do professor, denotando maneiras diversas de abordar o mesmo objeto.

O debate sobre gênero, mesmo que todos os professores entrevistados afirmem trabalhar com a temática em sala de aula, encontramos apenas em quatorze programas, num total de nove campi; contudo, apenas dois campi/programas definem o tema como uma unidade específica a ser estudada na disciplina de sociologia. Num deles, a unidade intitula-se "Questão de Gênero" e debate itens como: sexo e gênero, movimentos feministas, mulher e trabalho e mulher e política. No outro, o item se chama "Gênero, Política e Identidade" e apresenta os seguintes itens: a construção de gênero, identidade sexual e identidade de gênero, gênero no debate político, grupos LGBT e as concepções contemporâneas de gênero, gênero e multiafetividades.

Os demais doze programas (em sete campi) mencionam a discussão sobre gênero como subitens dentro de outras categorias, conforme quadro abaixo.

\section{Quadro 1 - A transversalidade de gênero nos programas da sociologia no IFSul.}

\begin{tabular}{|c|c|}
\hline Unidade & Subitem \\
\hline Desigualdades, diferença e equidade & A situação da mulher e dos afro-brasileiros no Brasil \\
\hline Cidadania e movimentos sociais & Movimentos feministas e de livre orientação sexual \\
\hline Cidade e globalização & Sexualidade e relações de gênero \\
\hline Sociologia do trabalho & $\begin{array}{l}\text { Identidades sociais e de gênero no mundo do trabalho; } \\
\text { variáveis no acesso e permanência no mercado de trabalho } \\
\text { - gênero; as mulheres e o mercado de trabalho }\end{array}$ \\
\hline Formas de participação política & $\begin{array}{l}\text { Movimentos sociais: igualdade de gênero e livre orientação } \\
\text { sexual }\end{array}$ \\
\hline Instituições sociais & Gênero e sexualidade \\
\hline Preconceito e discriminação & Gênero \\
\hline Estratificação social & Desigualdade de gênero \\
\hline Cultura & $\begin{array}{l}\text { Preconceito de gênero; gênero: identidade de gênero e } \\
\text { sexual e movimentos de afirmação }\end{array}$ \\
\hline
\end{tabular}

Fonte: Elaboração própria.

A variedade de inserções do gênero nos currículos da disciplina de sociologia no IFSul nos remete à compreensão de que ele "também pode ser pensado como uma 
categoria relacional, que precisa ser entendida em associação a outras categorias, mas não reduzida a elas" (MATOS; SCHMIDT; ARANTES; 2013, p. 215).

O mesmo foi observado na análise dos conceitos de gênero no material didático de sociologia oferecido pela rede estadual de São Paulo. Nele, a questão de gênero é tratada como um tema transversal, mesmo que a sexualidade e o gênero sejam compreendidos "como elementos de significados culturais e que devem ser abordados dentro de uma visão sociológica" (ARAUJO, 2016, p.7). A autora encontrou o debate a respeito da temática em três circunstâncias no âmbito dos conteúdos programáticos de sociologia: a diferenciação de gênero enquanto um elemento da estratificação social e da organização social; violência de gênero; e como situação política, ao tratar dos movimentos sociais.

A abordagem transversal da questão de gênero é observada igualmente pelos docentes de sociologia do IFSul. Independentemente de estar nomeada ou não nos programas das disciplinas, obtivemos vários relatos de professores que consideram a temática como algo que perpassa todo o conteúdo de sociologia, que direta ou indiretamente está presente em diferentes momentos do debate em sala-de-aula, sendo muitas vezes demanda dos próprios alunos (debates no grêmio estudantil, movimentos políticos como ocupações, acontecimentos do cotidiano), especialmente pelas meninas, que são as protagonistas da discussão, as que se envolvem mais com o tema, a despeito do fato de alguns professores também mencionarem uma onda crescente de conservadorismo e machismo entre os alunos. Algo semelhante havia sido apreendido na análise da constituição de uma política de gênero no Colégio Pedro II, onde as alunas presentes aos encontros "reivindicaram o protagonismo na discussão, já que a demanda pela temática de gênero e sexualidade partiu dos estudantes" (FERREIRA, 2016, p.13).

Talvez a percepção de maior iniciativa feminina neste debate esteja relacionada ao fato de que, em sua maioria, a abordagem sobre gênero no desenvolvimento da disciplina de sociologia ainda parece se concentrar nas questões relativas às mulheres em maior proporção do que incursões que também envolvam a identidade de gênero, orientação sexual, masculinidades, enfim, temas inscritos no complexo debate teórico sobre relações sociais de gênero, para além da discussão sobre a condição das mulheres na sociedade (movimento feminista, participação política, mercado de trabalho, violência, etc.).

Tal compreensão torna possível abordar o assunto em diversas oportunidades, fazendo com que a categoria gênero interaja com outros conteúdos, tornando-se assim um tema transversal que complementa e integra outros assuntos. Outrossim, segundo relatos dos professores, a discussão de gênero extrapola a sala de aula, por meio da constituição, em grande parte dos campi, de Núcleos de Estudos sobre Gênero e Sexualidade, a proposição de oficinas sobre o tema, conversas fora do horário de aula, grupos de estudos e orientação de projeto sobre gênero e feminilidades, por exemplo.

Além disso, quando nos referimos ao debate de gênero especificamente nas aulas de sociologia, importa saber quais são as estratégias didático-metodológicas que os docentes 
da disciplina no IFSul têm adotado. A análise das respostas a essa questão demonstra uma variedade muito grande de maneiras empregadas a fim de levar a cabo esta discussão: aulas expositivo-dialogadas; exibição de filmes, documentários e curtas-metragens; realização de seminários e apresentação de trabalhos; realização de exercícios; análise de músicas, propagandas, imagens e notícias veiculadas em jornais; leitura de textos base (sobre feminismo e tópicos de história); introdução ao debate a partir de questões motivadoras, exemplos do cotidiano, além de provocações mediadas, no intuito de apontar algo que está naturalizado com a intenção de desconstruir essa naturalização; e a utilização de exemplos extremos, chocantes e com maior capacidade de impactar os jovens, despertando sua atenção para o tema.

Ademais, faz-se uso da literatura como provocação ao debate; ditados populares; debates e discussões considerando posições divergentes; realização de palestras; foco nas diferenças entre homens e mulheres vivenciadas nas instituições sociais a fim de provocar reflexões nas concepções dos próprios alunos a respeito da temática; articulação entre abstração, teoria, conceitos e o concreto, a partir de exemplos e investigações realizadas pelos alunos. São também consideradas as narrativas biográficas, histórias de vida, nas quais, segundo relatam os docentes, emergem casos de assédio, violência contra a mulher e relações abusivas nos relacionamentos amorosos. A realização de dinâmicas é outra estratégia adotada nas aulas de sociologia para debater a questão de gênero, por exemplo, no caso das profissões, problematizando os locais de trabalhos tradicionalmente destinados a homens e mulheres ou a inversões de papéis, o uso deste recurso como um exercício de alteridade, quando, por exemplo, a dinâmica gira em torno das piadas sexistas dirigidas aos meninos como elemento motivador da discussão sobre homofobia, machismo e assédio.

Chama atenção o fato de que, em alguns casos, há uma resistência maior do debate sobre as questões de gênero, fazendo com que os professores busquem como alternativa metodológica a utilização de dados de pesquisa, gráficos e dados estatísticos para avançar na discussão. Conforme relato de um professor, ao tratar do tema a partir de pesquisas quantitativas e dados divergentes que "se chocam com o senso comum", existiria surpresa por parte dos alunos, por exemplo, quando é mencionada a maior presença feminina nas universidades, dados relativos à violência doméstica contra homens e abordagens de conceitos como "família disfuncional". Ao que parece, esta abordagem a respeito da temática gênero se afasta em parte das demais aproximações observadas entre os docentes, no sentido de que o "senso comum" não consideraria uma realidade em que os homens também são oprimidos, por vezes, pelas mulheres. Fica em aberto para escritos futuros o significado desta concepção de relações de gênero no âmbito do ensino de sociologia no ensino médio.

Por outro lado, identificou-se também certa preocupação, manifestada por alguns docentes, em não fazer diferenciação entre a abordagem dessa questão e dos demais 
temas tratados pela sociologia, pois seria um tópico como outro qualquer. Segundo um professor "Gênero é outro tema da sociologia, há 'naturalização' do seu debate", quer dizer, a fim de problematizar o que está socialmente posto em termos da construção das identidades de gênero e tudo o que diz respeito ao tema, seria preciso tornar cotidiana essa discussão em sala-de-aula.

Entendemos que, a partir dessas informações, os docentes no IFSul, em sua maioria absoluta, têm lançado mão de uma série de técnicas de ensino a fim de problematizar a questão de gênero e construir a compreensão da realidade social desde uma perspectiva sociológica. Mais que isso, têm tentado desnaturalizar os processos sociais, olhar de maneira a estranhar a sociedade em que vivem seus educandos, problematizar a compreensão das relações sociais, recusando explicações essencialistas, esse que é, conforme descreveram Oliveira (2014), Passamani (2016) e Osório; Sarandy (2016), o próprio objetivo da inclusão da sociologia no ensino médio.

\section{Considerações finais}

Ao debater o ensino de sociologia no IFSul este artigo buscou dar especial ênfase à discussão sobre gênero no desenvolvimento da disciplina. Considerando a não existência de um currículo nacional comum e levando em conta os documentos nacionais que orientam o ensino da sociologia no Brasil, nota-se que a questão de gênero é considerada um tema transversal, não lhe sendo atribuído o status de categoria analítica da realidade social. Ora, ao compreendê-la como um componente que estrutura a sociedade, seria possível também concebê-la como um tópico específico nos conteúdos a serem trabalhados na área de humanas, particularmente na sociologia. Se não há esse entendimento expresso nas orientações nacionais, também não há uma proibição explícita, apesar das tentativas de determinados grupos em criminalizar os docentes que problematizam o tema do gênero nas escolas.

Sendo assim, os dados coletados nos permitem afirmar que todos os campi abordam o tema em ao menos uma série do ensino médio, mesmo que de forma transversal e sem fazer parte dos conteúdos programáticos da disciplina. Dos 11 campi estudados, apenas dois destinam um tópico específico para debater gênero, os demais inserem essa discussão em outras questões: movimentos sociais, trabalho, política, socialização, entre outras, reconhecendo a importância dessa categoria analítica para a compreensão da realidade e desnaturalização de certos aspectos da vida social, mesmo que o debate esteja concentrado, em grande parte das abordagens, em torno de questões relativas às mulheres.

Frente a este entendimento, as técnicas de ensino escolhidas pelos docentes são múltiplas. Encontramos uma ampla gama de possibilidades para realizar essa discussão, desde leituras, debates, exposição de audiovisuais, pesquisas, narrativas biográficas, seminários, 
exemplos do cotidiano, entre outros. Tal observação evidencia que gênero é uma temática que pode ser tratada de diferentes formas, mais ou menos lúdicas, mas que tem um potencial enorme em termos da complexidade da apreensão da sociedade e das habilidades que os discentes podem desenvolver a partir de sua abordagem na disciplina de sociologia.

Recebido em: 21/08/2017 e aprovado em: 23/01/2018

\section{Notas}

1 Versão ampliada do trabalho apresentado no Congresso Internacional 13ํㅡㄴ Mundo de Mulheres \& Fazendo Gênero 11 - Transformações, Conexões, Deslocamentos, realizado em Florianópolis, Santa Catarina, de 30 de julho a 04 de agosto de 2017.

2 Contamos com a resposta de 21 docentes, dois não retornaram o questionário respondido, e um não respondeu ao contato.

3 Os cursos oferecidos são: Comunicação Visual, Eventos, Vestuário, Design de Interiores, Edificações, Plásticos, Refrigeração e Climatização, Química, Agroindústria, Meio Ambiente, Agropecuária, Controle Ambiental, Sistemas de Energias Renováveis, Automação Industrial, Mecatrônica, Eletroeletrônica, Eletrônica, Eletrotécnica, Eletromecânica, Informática para Internet e Informática.

4 No caso dos cursos oferecidos pelo campus Pelotas-Visconde da Graça, realizados em três e não em quatro anos como nos demais, para atender normativa interna que exige 40horas/aulas anuais, reformulações curriculares estão em curso para que a sociologia disponha de 1 hora/semanal em dois anos e 2 horas/aula em um dos anos do ensino médio.

\section{Referências}

ARAUJO, Natália Cristina Sganzella de. Currículo de Sociologia e Gênero: uma análise do material didático de Sociologia para Ensino Médio da Rede Pública de Educação de São Paulo. In: Encontro Estadual de História, 23. São Paulo. Anais. São Paulo: ANPUH, 2016. Disponível em: http://www.encontro2016.sp.anpuh.org/resources/anais/48/1467582182_ ARQUIVO_iculodeSociologiae GeneroumaanalisedomaterialdidaticodeSociologiapara EnsinoMediodaRedePublicadeEducacaodeSaoPaulo.pdf. Acesso em: 9 ago. 2017.

BRASIL. Ministério da Educação; Secretaria de Educação Básica; Secretaria de Educação Continuada, Alfabetização, Diversidade e Inclusão; Secretaria de Educação Profissional e Tecnológica. Conselho Nacional de Educação; Câmara de Educação Básica. Diretrizes Curriculares Nacionais Gerais da Educação Básica. Brasília: MEC; SEB; DICEI, 2013. Disponível em: <http://portal.mec.gov.br/index. php?option=com_docman\&view=download\&alias $=15548 \mathrm{~d}$-c-n-educacao-basica-nova-pdf \&Itemid $=30192>$. Acesso em: 23 mar. 2017.

. Ministério da Educação. Base Nacional Comum Curricular. Proposta preliminar. Segunda versão revista. Brasília: MEC, 2016. Disponível em: http://basenacionalcomum.mec.gov.br/a-base. Acesso em: 18 jun. 2017. 
BURILLE, Stephanie Natalie. Gênero e Sexualidades nas aulas de Sociologia: um olhar sobre a percepção discente. Revista Vernáculo, UFPR, n.36, 2o SEM./2015, p.196-224. Disponível em: http:// revistas.ufpr.br/vernaculo/article/view/37382. Acesso em: 31 maio 2017.

CARVALHO, Lejeune Mato Grosso Xavier de. A trajetória histórica da luta pela introdução da disciplina de Sociologia em ensino médio no Brasil. In: __ Sociologia e Ensino em Debate: experiências e discussões de Sociologia no Ensino Médio. Ijuí: Editora UNIJUÍ, 2004.p.17-28.

COSTA, Cristina. Sociologia: introdução à ciência da sociedade. São Paulo: Editora Moderna, 1997.

FERREIRA, Fátima Ivone de Oliveira. A contribuição da sociologia para a construção de uma política de gênero em uma escola de educação básica. Revista Perspectiva Sociológica, Rio de Janeiro: Espiral, número especial, p. 7-16, 2º sem. 2012/1ํㅗ sem. 2016. Disponível em: http://www.cp2.g12.br/ojs/index. php/PS/article/view/998/716. Acesso em:14 ago. 2017.

MARINHO, João; IERVOLINO, Thais; NICOLAV, Vanessa. Sem partido e sem educação? Conheça os projetos de lei que questionam a formação cidadã na sala de aula. Educação \& Participação, 30 jun. 2016. Disponível em: <https://educacaoeparticipacao.org.br/acontece/sem-partido-e-sem-educacao/>. Acesso em: 13 ago. de 2017.

MATOS, Juliana Almeida; SCHMIDT, Tcharles Gonçalves; ARANTES, Marco Antonio. Relações de gênero: uma problematização acerca da ausência de discussões no âmbito do ensino médio. Tempo da Ciência, Toledo: Unioeste, v. 20, n. 40, p.209-222, 2º sem. 2013. Disponível em: http://e-revista.unioeste. br/index.php/tempodaciencia/article/view/10055/0. Acesso em: 31 maio 2017.

OLIVEIRA, Amurabi. Os desafios teórico-metodológicos do Ensino de Sociologia no Ensino Médio. Perspectiva, Florianópolis: UFSC, v. 32, n. 3, p. 1019-1044, set./dez. 2014. Disponível em:<https:// periodicos.ufsc.br/index.php/perspectiva/article/viewFile/2175-795X.2014v32n3p1019/29918>. Acesso em: 7 nov. 2016.

OSÓRIO, Andréa; SARANDY, Flávio. Uma palavra sobre o silêncio: conteúdos de gênero para sociologia nos PCN, OCN e BNC. Inter-Legere, Natal: UFRN, n. 18, p. 58-75, jan./jun. 2016. Disponível em: https://periodicos.ufrn.br/interlegere/article/view/10814. Acesso em:31 maio 2017.

PASSAMANI, Guilherme Rodrigues. As temáticas de gênero, sexualidade e diversidade sexual no ensino médio: interface entre a institucionalização da Sociologia e a extensão universitária. Contemporânea, São Carlos: UFSCar, v. 6, n. 1, p. 119-132, jan.jjun. 2016. Disponível em: <http://www. contemporanea.ufscar.br/index.php/contemporanea/article/view/400>. Acesso em: 31 maio de 2017.

ROSA, Russel Teresinha Dutra da. Reforma do Ensino Médio, Projeto Escola sem Partido e a Pedagogia de Paulo Freire. In: Encontro Sobre o Poder Escolar, 13, Pelotas, 2017. Comunicação oral.

SILVA, Ileizi Luciana Fiorelli. O ensino das Ciências Sociais/Sociologia no Brasil: histórico e perspectivas: introdução. In: MORAES, Amaury César. Sociologia: ensino médio. Brasília: Ministério da Educação, Secretaria de Educação Básica: 2010. p. 15-44. Disponível em:<http://portal.mec.gov.br/ index.php?option=com_docman\&view=download\&alias=7843-2011-sociologia-capa-pdf\&category_ slug=abril-2011-pdf\&Itemid=30192>. Acesso em: 7 nov. 2016.

VIANNA, Claudia Pereira; UNBEHAUM, Sandra. O gênero nas políticas públicas de educação no Brasil: 1988-2002. Cadernos de Pesquisa, São Paulo: FCC, v. 34, n. 121, p. 77-104, jan./abr. 2004. Disponível em: <http://www.scielo.br/pdf/cp/v34n121/a05n121.pdf>. Acesso em: 17 jun. 2017. 